The texts that make up the sections of issue 41 of Interface - Comunicação, Saúde, Educação portray the special attention given by this journal to manifestations of the diversity of academic disciplines, topics, subjects and theoretical-methodological approaches, at the same time that these converge towards the major themes emphasized in the journal's editorial line that are so pertinent in the debate around possible dialogue among the different fields of knowledge and practices within healthcare. Prominent among these are contributions on the meanings and sense of professional practices and rationales within the field of healthcare and their possible relationship to service users; the presence of biomedical rationales in the media; and significant learning among users in their educative processes and also among healthcare professionals in their specific training processes. In analytical texts or in reports on experiences resulting from field research, the choice of qualitative methodology is highlighted: this is more appropriate for the topics covered and is coincidentally the topic of the book by Ana Maria Canzonieri, "Metodologia da pesquisa qualitativa na saúde" (Qualitative research methodology in healthcare), presented in the Books section.

The meanings and sense of the practices and rationales of healthcare professionals and service users are revealed through a variety of topics in the following articles: "STD/AIDS counseling for pregnant women who underwent the anti-HIV test on admission for delivery: the meanings of practice"; "Therapeutic itineraries: paths crossed in the search for care"; "Signs, meanings and practices of crisis management in psychosocial care centers"; "Distinct approaches towards anabolic steroids: risks to health and hypermasculinity"; and "Young men's discourses regarding access to healthcare services". These articles particularly manifest the authors' concerns regarding relationships and dialogue between professionals and users, and seek to point out possible solutions that take into consideration the subjective views, motivations and sociocultural contexts within which experiences unfold, and also indicate the need to go deeper into topics that are still little known, such as hypermasculinity. Taking another line of analysis, the articles "The visibility of nursing work in the surgical center through photography" and "Contributions to the construction of Integrative and Complementary Nutrition" can be highlighted. These deal specifically with biomedical practices and rationales, and the implications and possibilities of expanding this perspective for proposing healthcare practices that are more appropriate to users' realities.

Also in relation to biomedical rationales, two articles analyze its presence in the media: "Drug advertising: health as a consumer product" and "Modest witnesses and invisible populations in media coverage of human genetics in Colombia". These articles point out problems and constraints relating to a broad sense of communication, when this perspective is appropriated by the media.

Significant learning among users in their educative processes is covered in the articles "Health education in the context of family health from the user's perspective" and "Functional health literacy: reflections and concepts on its impact on the interaction among users, professionals and the health system". These articles emphasize the need for changes in healthcare practices through educational strategies that favor significant learning processes that improve communication between professionals and healthcare service users. From the perspective of improvement of communication and dialogue among these social players, the contribution of the article "Dialogue with Bakhtin: some contributions to the understanding of verbal interactions in the health field" can be highlighted.

Significant learning also comes into the discussion on the specific training processes of healthcare professionals. In the articles "Being a mentor in medicine: an archetypal view on motivations and changes in the journey" (medical 
education) and "The dialogic process of knowledge construction in Discussion forums" (higher education through distance learning), the importance of perspectives involving dialogue and mutual transformation in the process of knowledge construction is highlighted.

A critical perspective on the education and training processes is also present in the reports on experiences in the Open Space section. The texts "Collaborative learning networks: the contribution of distance education in the qualification process for managers of the Brazilian National Health System - SUS", "Physical education in mental health: constructing development from an interdisciplinary perspective" and "Occupation, wellness and life-satisfaction: the experience of an alternative training model within occupational therapy in Australia" emphasize the importance of "mutual significant learning" and interaction or "intercognition", which are made possible through contact with other people, especially within non-traditional learning contexts. The viability of these shifts in training processes is linked to changes in pedagogical processes and curricular practices, as covered in the text "Integrated curriculum for teaching dentistry: new directions for training in the field of healthcare".

In making it possible to bring the discussion on educational and training processes closer to approaches towards the meanings and senses of the practices and rationales of professionals and healthcare service users, the texts that make up this issue of Interface converge with important contributions towards reflecting on and changing practices, such that they favor communication between these different social players, thereby making these practices more comprehensible and significant in different contexts.

\section{Eunice Nakamura}

Area editor

Interface - Comunicação, Saúde, Educação 